Dear Author,

Please, note that changes made to the HTML content will be added to the article before publication, but are not reflected in this PDF.

Note also that this file should not be used for submitting corrections. 


\section{AUTHOR QUERY FORM}

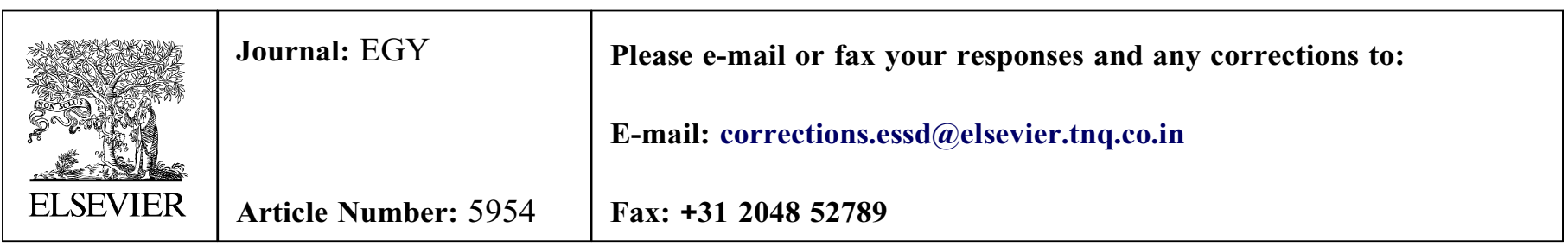

Dear Author,

Please check your proof carefully and mark all corrections at the appropriate place in the proof (e.g., by using on-screen annotation in the PDF file) or compile them in a separate list. Note: if you opt to annotate the file with software other than Adobe Reader then please also highlight the appropriate place in the PDF file. To ensure fast publication of your paper please return your corrections within 48 hours.

For correction or revision of any artwork, please consult http://www.elsevier.com/artworkinstructions.

Any queries or remarks that have arisen during the processing of your manuscript are listed below and highlighted by flags in the proof.

\begin{tabular}{|c|c|}
\hline $\begin{array}{l}\text { Location } \\
\text { in article }\end{array}$ & $\begin{array}{l}\text { Query / Remark: Click on the } Q \text { link to find the query's location in text } \\
\text { Please insert your reply or correction at the corresponding line in the proof }\end{array}$ \\
\hline Q1 & Please check affiliation 'a' and correct if necessary. \\
\hline Q2 & Please check the keywords and correct if necessary. \\
\hline Q3 & $\begin{array}{l}\text { Please note that Refs. [30,39] have been provided in the reference list but not cited in the text. Kindly give } \\
\text { citations for them. }\end{array}$ \\
\hline Q4 & Please check Ref. [22] and correct if necessary. \\
\hline Q5 & Please confirm that given names and surnames have been identified correctly. \\
\hline & $\begin{array}{l}\text { Please check this box or indicate } \\
\text { your approval if you have no } \\
\text { corrections to make to the PDF file }\end{array}$ \\
\hline
\end{tabular}

Thank you for your assistance. 


\section{Energy}

\section{Highlights}

- A novel air cooled condenser for CSP (Concentrated Solar Power) applications is proposed.

- A thorough experimental analysis of various condenser designs was performed.

- Heat transfer and flow friction correlations validated for fan generated air flow.

- A thermodynamic model to calculate CSP plant output is presented.

- Results show the proposed condenser design can continually optimise plant output. 


\title{
Modelling the thermodynamic performance of a concentrated solar power plant with a novel modular air-cooled condenser
}

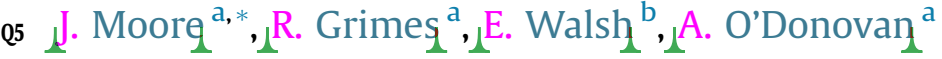 \\ Q1 a Stokes Research Institute, ER1-002, University of Limerick, Castletroy, Limerick, Ireland \\ ${ }^{\mathrm{b}}$ Osney Thermo-Fluids Laboratory, University of Oxford, Oxford, UK
}

\section{A R T I C L E I N F O}

Article history:

Received 20 October 2013

Received in revised form

1 March 2014

Accepted 6 March 2014

Available online $\mathrm{xxx}$

\section{Keywords:}

Dry cooling

Air-cooled condenser

Air-cooled heat exchanger

CSP (Concentrated Solar Power) system

\begin{abstract}
A B S T R A C T
This paper aims at developing a novel air-cooled condenser for concentrated solar power plants. The condenser offers two significant advantages over the existing state-of-the-art. Firstly, it can be installed in a modular format where pre-assembled condenser modules reduce installation costs. Secondly, instead of using large fixed speed fans, smaller speed controlled fans are incorporated into the individual modules. This facility allows the operating point of the condenser to change and continuously maximise plant efficiency. A thorough experimental analysis was performed on a number of prototype condenser designs. This analysis investigated the validly and accuracy of correlations from literature in predicting the thermal and aerodynamic characteristics of different designs. These measurements were used to develop a thermodynamic model to predict the performance of a 50 MW CSP (Concentrated Solar Power) plant with various condenser designs installed. In order to compare different designs with respect to the specific plant capital cost, a techno-economic analysis was performed which identified the optimum size of each condenser. The results show that a single row plate finned tube design, a four row, and a two row circular finned tube design are all similar in terms of their techno-economic performance and offer significant savings over other designs.
\end{abstract}

() 2014 Published by Elsevier Ltd.

\section{Introduction}

ACC's (Air-Cooled Condenserş) can potentially reduce the water consumption of a power plant by up to $97 \%$ [1]. This is particularly significant for CSP (Concentrated Solar Power) plants which are typically located in extremely dry regions, where water for wet cooling systems is scarce. In many cases an air-cooled condenser may be the only feasible option for a CSP plant. However, the high operating costs and the corresponding hit on plant efficiency associated with an air-cooled condenser makes it an unpopular option and there is a clear requirement for a more efficient dry cooling system for CSP plants [1]. This is seen as a significant barrier to the development of CSP plants in many regions around the world. In Europe, the SET plan (Strategic Energy Technology Plan) [2] describes the potential for CSP to contribute 2.5\% of the EU's energy by 2020 . The SET plan directly highlights water availability in plant locations as a significant issue which must be addressed for CSP development. This paper is aimed towards the development of a novel air-cooled condenser which - compared to plants cooled by

\footnotetext{
* Corresponding author.

E-mail address: james.moore@ul.ie (J. Moore).
}

conventional ACCs - can potentially enhance CSP plant efficiency and reduce installation costs.

The current state of the art in air-cooled condensers consists of a series of rectangular plate finned tubes coupled with very large axial fans (approximately $10 \mathrm{~m}$ diameter), operated at a constant speed. These condensers have a number of inherent design issues. The fact that the fans usually operate at a constant speed means that most condensers continuously operate at one point only, and cannot adapt to an optimum operating point given the changing ambient conditions. Walsh et al. [3] highlighted some additional performance limitations of these condensers where they measured the air flow at the outlet of the tube bundle across one cell. The investigation showed that the heat removal is non-uniform across each cell and large regions of ineffectiveness are consistently present. The proposed condenser design considers the heat sink and fan array as a composite solution and employs much smaller (approximately $1 \mathrm{~m}$ diameter), speed controlled fans. Additionally, it is envisaged that the condenser and fan array be incorporated into a pre-assembled module and instead of erecting the very large existing ACC structures, that an array of smaller modules be installed. It is expected that this concept will offer significant installation cost savings. This paper particularly focuses on the airside performance of the condenser as this is the dominant thermal 


\begin{tabular}{|c|c|c|c|}
\hline \multicolumn{2}{|c|}{ Nomenclature } & $r$ & discount rate \\
\hline & & $r_{h}$ & $A_{\min } L / A, \mathrm{~m}$ \\
\hline$A$ & heat transfer area, $\mathrm{m}^{2}$ & $r_{j}$ & specific tube row \\
\hline$A_{\min }$ & free-flow area, $\mathrm{m}^{2}$ & $u_{\max }$ & air velocity at minimum cross section, $\mathrm{m} / \mathrm{s}$ \\
\hline$C$ & cost, US\$/€ & $x$ & duct depth (in flow direction), $\mathrm{m}$ \\
\hline Cc & capital cost, US\$/€ & $f$ & friction factor \\
\hline$C_{\min }$ & minimum capacity rate, $\mathrm{W} / \mathrm{K}$ & $\operatorname{Re}$ & Reynolds number \\
\hline$D$ & fan diameter, m & $\mathrm{Nu}$ & Nusselt number \\
\hline$H$ & fin height (plate fins), m & $\operatorname{Pr}$ & Prantdl number \\
\hline Kc & coefficient for sudden contraction & St & Stanton number \\
\hline Ke & coefficient for sudden expansion & $\delta$ & fin thickness, m \\
\hline$L$ & length of tube bank in flow direction, $m$ & $\varepsilon$ & effectiveness \\
\hline$M$ & mass, $\mathrm{Kg}$ & $\eta_{\text {surf }}$ & surface effectiveness \\
\hline$N$ & fan speed, rpm & $\mu$ & dynamic viscosity, $\mathrm{Kg} / \mathrm{m} \mathrm{s}$ \\
\hline$P_{\text {fans }}$ & power, W & $\rho$ & air density, $\mathrm{Kg} / \mathrm{m}^{3}$ \\
\hline$Q$ & heat power, $\mathrm{W}$ & $\sigma$ & ratio of free-flow to frontal area \\
\hline$S_{d}$ & diagonal pitch, m & & \\
\hline$S_{f}$ & $1 / n_{f}$ & Subscri & \\
\hline$S_{l}$ & longitudinal pitch, m & $a$ & air \\
\hline$S_{t}$ & transverse pitch, m & alum & aluminium \\
\hline$T$ & temperature, $\mathrm{K}$ & $c$ & Condensate \\
\hline$U$ & overall thermal conductance, $\mathrm{W} / \mathrm{m}^{2} \mathrm{~K}$ & $f$ & Fin \\
\hline$W$ & plate fin tube width, $\mathrm{m}$ & $i$ & heat exchanger inlet \\
\hline$Z$ & fan to heat exchanger distance, $m$ & $m$ & mean \\
\hline$b$ & fin pitch (plate fins), m & 0 & heat exchager outlet \\
\hline$c_{p}$ & specific heat capacity, J/Kg K & $t$ & year of operation \\
\hline$d_{\mathrm{ex}}$ & tube exterior diameter, m & $s$ & steam \\
\hline$d_{\text {fin }}$ & fin exterior diameter, $\mathrm{m}$ & steel & steel \\
\hline$d_{h}$ & hydraulic diameter $\left(4 \times r_{h}\right)$, m & $\infty$ & ambient \\
\hline$h$ & heat transfer coefficient, $\mathrm{W} / \mathrm{m}^{2} \mathrm{~K}$ & & \\
\hline$h_{f g}$ & enthalpy of vaporisation, $\mathrm{kJ} / \mathrm{Kg}$ & Abbrev & tions \\
\hline$k$ & thermal conductance, $\mathrm{W} / \mathrm{m} \mathrm{K}$ & ACC & air cooled condenser \\
\hline$l$ & fin height (circular fins), m & CSP & concentrated solar power \\
\hline$\dot{m}$ & mass flow rate, $\mathrm{Kg} / \mathrm{s}$ & DNI & direct normal irradiance, $\mathrm{kWh} / \mathrm{m}^{2}$ \\
\hline$n_{f}$ & number of fins per meter & FD & forced draft \\
\hline$n_{r}$ & number of tube rows & ID & induced draft \\
\hline$n_{t}$ & number of tubes per row & LCOE & levelised cost of electricity, $€ / \mathrm{kWh}$ \\
\hline$p$ & pressure, $\mathrm{Pa}$ & MACC & modular air-cooled condenser \\
\hline
\end{tabular}

resistance, particularly determining the appropriate balance between heat transfer and fan power consumption. A model was developed to investigate the effect of various design parameters on the performance of a $50 \mathrm{MW}$ parabolic trough CSP plant.

A number finned tube designs were considered as possible heat exchanger surfaces and a series of tests were performed to determine their thermal and aerodynamic characteristics in order to model the effect of the condenser designs on power plant performance. The availability of different tube designs to manufacture full-scale prototypes in a realistic time frame constrained the options to a multi-row design consisting of a bank of circular finned tubes, or a single row of plate finned, elongated rectangular tubes, similar to those in many existing ACC designs. The initial prototype condenser module which was tested contained six rows of helically finned round tubes in a staggered, equilateral arrangement, like that shown in Fig. 1(a) and (b) and had a square face area of $4 \mathrm{~m}^{2}$. As the air-flow through such a tube bank is chaotic, no simplified theory is available to predict heat transfer and friction characteristics. However, extensive experimental research has been performed on such designs and correlations exist to predict their performance. Many of these correlations [4-6] are only valid for a tube bundle with a minimum of four-six tube rows. Below four tube rows, vast changes occur in the flow field which affect turbulence levels and inlet and exit flow losses. The inlet and exit losses are due to a flow contraction at the heat exchanger core entrance and a flow expansion at the core exit. These effects are described in further detail in Kays and London [7]. Monheit [8] also describes flow losses which are inherent in an equilateral staggered tube arrangement due to the flow continuously accelerating and decelerating through the bank. Zukauskas [9] describes the effect of turbulence on the heat transfer in a tube bundle stating that the heat transfer in the inner tube rows may exceed by $30-70 \%$ that of the first row depending on the longitudinal pitch. In contrast to the circular finned tube design, the air-flow through the plate-finned tube design shown in Fig. 1(c) and (d) can be simplified to laminar rectangular duct flow, for which theoretical models exist to predict heat transfer and pressure drop. Flow through a duct comprises a developing region through a finite entrance length after which point the flow becomes fully developed throughout the remainder of the duct. The developing region occurs where the boundary layers over the duct walls are distinct and the core or free stream fluid does not experience the viscous presence of the walls [10]. In order to account for both regions a composite model must be employed. By applying an energy balance across the duct [11] and [12] have developed relationships to predict heat transfer and friction characteristics. 


\begin{abstract}
Single circular
finned tube
\end{abstract}
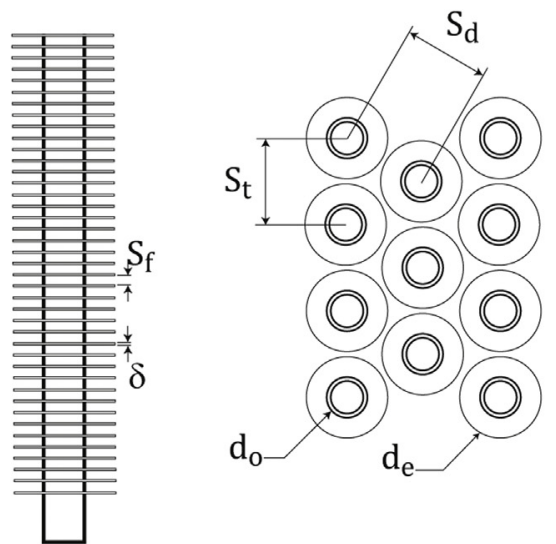

(a)

Pictorial view of a circular finned tube

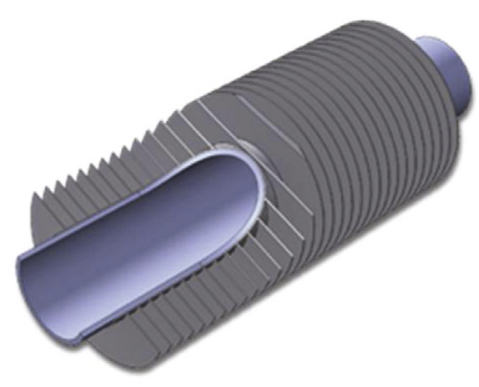

(b)
Plate finned tube end view
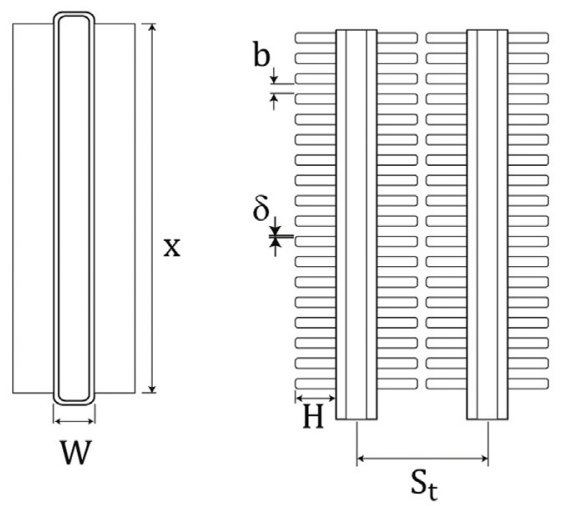

(c)

Pictorial view of plate finned tube bundle

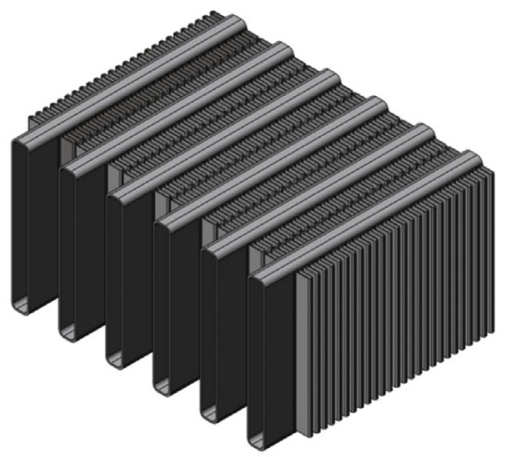

(d)

Fig. 1. Diagram of the proposed condenser designs, (a) a multi-row circular finned tube bank; (b) a single row of rectangular plate finned tubes; (c) pictorial view of circular finned tube and (d) pictorial view of plate finned tube bundle.

Another investigation by the authors [13] highlights and explains a fundamental design problem with a single pass, multi-row condenser commonly known as backflow. This phenomenon is less prevalent in heat exchangers with fewer tube rows, and so it was deemed necessary to extend the investigation on circular finned tube designs beyond the original six row design and study the performance of circular finned tube heat exchangers with fewer tube rows. It was also expected that reducing the number of tube rows would yield a higher heat rejection to fan power ratio as the flow resistance would be substantially reduced. Nir [14], Gianolio \& Cuti [15] and T'Joen et al. [16] all presented work on the performance of finned tube banks with less than six tube rows. In some cases coefficients were developed to combine with existing correlations which compensated for the reduction in heat transfer performance. Wang et al. [17] describe various experimental test procedures for characterising heat exchanger surfaces and highlight the fact that much of the published experimental data may not agree well for various reasons such as fin to tube contact, several different data reduction methods and experimental error. Monheit [8] reports that air-flow conditions and background turbulence levels also vary for different investigations and contribute to discrepancy in experimental results. It is evident from a review of the literature that the vast majority of the relevant correlations were developed for wind tunnel air flows which are generally conditioned in large settling chambers resulting in steady, parallel flow with uniform velocity. This does not replicate realistic flow fields generated by axial fans which contain significant swirl, unsteadiness and velocity non-uniformity. Due to this, experimental measurements were required to firstly determine the accuracy of existing correlations in the prediction of heat transfer and pressure drop of the proposed designs and secondly to investigate the validly of certain correlations in a realistic fan generated air-flow. To the best knowledge of the authors, other than the measurements of [15] no other measurements of heat exchanger performance in realistic fan flows have been published, and the measurements of [15] were for a limited range of geometric parameters.

Two sets of experiments were carried out. Firstly, full scale measurements were performed on a prototype whose face area was $2 \mathrm{~m} \times 2 \mathrm{~m}$, which was cooled by four $1 \mathrm{~m}$ diameter axial flow fans and contained six rows of circular finned tubes. It was not feasible to test every configuration at a full-scale level so a reduced scale test rig was designed. Condensers with different geometries were 
examined in this test facility and the most promising design, a four row circular finned design, was then tested at a full scale to verify the reduced scale measurements. Full scale measurements on the plate fin design were also performed to validate the relevant theoretical models. The reduced-scale measurements were performed by constructing a condenser core in a wind tunnel working section. In the wind tunnel, the finned tubes were then subject to a highly uniform flow field, similar to many other studies $[4,6,14]$ and [16]. In the case of the full-scale measurements, the fan bank provided a realistic flow field and fan to heat exchanger distance as well as fan orientation (forced or induced draft) were additional variables. Both scenarios have very different flow field attributes which can have an effect on both heat transfer and pressure drop. The authors [18] previously investigated this, as did Gianolio and Cuti [15] who found that in terms of heat transfer, there was very little effect for a heat exchanger with a high effectiveness. However for a heat exchanger with less tube rows, or lower effectiveness, there are potential gains in terms of heat transfer associated with a forced draft flow field compared to induced draft. In an effort to characterise each flow field, a series of velocity sensors were traversed across the inlet of the condenser to generate a velocity contour plot.

The evaluation of heat exchanger performance is typically limited to metrics such as coefficient of performance. However, for a steam plant condenser such a measure is not an appropriate performance indicator. A more telling indication of performance is the effect of condenser design on overall plant performance. This paper combines the experimental measurements of condenser thermal and aerodynamic characteristics with the characteristics of a typical $50 \mathrm{MW}$ parabolic trough CSP plant steam turbine to predict the effects of condenser design on power plant thermodynamic performance. To the knowledge of the authors, this is the first time that such a thorough evaluation of condenser design in terms of power plant performance has been published. Deng and Boehm [19] simulated two different tube types to investigate the effect on the Rankine cycle efficiency. However no effort was made to investigate the corresponding effects on condenser fan power consumption and essentially simulated two different air-side heat transfer coefficients. Other studies such as that of [20] and [21] have simulated plant performance using commercial software to investigate effects of storage systems and other plant auxiliary components. In these cases condenser performance was fixed and not considered as a significant variable.

The model developed in this study predicts the thermodynamic performance of the plant with various condenser designs installed, various sizes (number of modules) and at different ambient conditions. The results of this analysis show a primary advantage of the technology; irrespective of the condenser design, size or ambient conditions there is an optimum fan speed which yields the maximum net output power. The variable speed fans can continuously adapt to maintain maximum possible plant efficiency. While this will require tight fan speed control, it offers a significant advantage over the current state-of-the-art where such speed control is rarely provided. To achieve a more complete means of comparing the different designs and identifying which condenser design maximises output at minimum cost, a techno-economic analysis was performed to calculate the LCO (Levelised Cost Of Electricity) for each design. LCOE is a standard means of comparing different technologies and integrates thermodynamic and economic performance in a single metric [22]. Not only does this identify the best design for a given plant capital cost, but it also identifies the optimum size for each condenser design. This analysis normalises the performance data of the novel condenser design so it can be considered for scenarios other than the $50 \mathrm{MW}$ parabolic trough CSP case considered in this study.
The primary objectives of this study are as follows:

- Experimentally investigate the accuracy of the relevant correlations in predicting the pressure drop and heat transfer through the various condenser designs

- Experimentally validate correlations from literature with heat exchangers subject to fan generated flow fields

- Measure the flow field at the condenser inlet for both the forced draft and induced draft scenario and determine the effect on thermal and aerodynamic characteristics

- Develop a thermodynamic model which allows condenser design to be evaluated in terms of power plant performance

- Integrate condenser cost and CSP plant capital expenditure estimations with the thermodynamic model and compare different condenser designs based on a techno-economic analysis.

\section{Theory}

In this section correlations and theory from literature, which predict the air-side pressure drop and heat transfer in the various condenser designs are presented. For the circular finned tube designs as seen in Fig. 1(a) and (b), experimental data has been correlated in terms of a dimensionless flow rate parameter, Reynolds number. For the plate finned design as illustrated in Fig. 1(c) and (d), theoretical models predict friction and heat transfer characteristics in the entrance and fully developed region of the finned ducts also in terms of Reynolds number.

\subsection{Pressure drop}

Equation (1) is the correlation of Robinson and Briggs [4] which was used to predict the dimensionless friction factor across a circular finned tube heat exchanger. The correlation is valid in the flow range of $2000<R e<50,000$. The Reynolds number range through the prototype condenser module ranges from 2000 to 25,000.

$f=9.465 R e^{-0.316}\left(\frac{S_{t}}{d_{\mathrm{ex}}}\right)^{-0.927}\left(\frac{S_{t}}{S_{d}}\right)^{0.515} \frac{n_{r} d_{h}}{L}$

where,

$R e=\frac{d_{\mathrm{ex}} \dot{m}_{a}}{\mu A_{\min }}$

Equation (2) is the correlation of Nir [14] for the friction factor over a tube bank with plain fins within $300<R e_{d h}<10,000$, where $R e_{d h}$ is the Reynolds number based on the hydraulic diameter, $d_{h}$, and $K_{p}$ is a coefficient to account for different number of tube rows.

$f=2.12 R e_{d_{h}}^{-0.25}\left(\frac{A_{\mathrm{min}}}{A}\right)^{-0.55}\left(\frac{d_{\mathrm{fin}}}{d_{\mathrm{ex}}}\right)^{-0.25} K_{p}$

Equation (3) presents the correlation of T'Joen et al. [16] for the friction factor across a single row, finned tube heat exchanger. This correlation remains valid inside $1000<R e<15,000$.

$f=2.271 R e^{-0.325}\left(\frac{S_{t}}{d_{\mathrm{ex}}}\right)^{-1.849}$

Equation (4) is a composite model developed by Culham and Muzychka [23] to predict the friction factor Reynolds number product through a heat sink duct and can be used to estimate plate fin tube pressure drop. The model employs the intersection of asymptotes method originally developed by Churchill and Usagi [24] 
which combines the developing and developed flow regions. Equations (5) and (6) are the Reynolds number friction factor product through the developing and fully developed regions for a constant rectangular cross section [23]. The Reynolds number in this case is based on the hydraulic diameter of the duct, where the hydraulic diameter is equal to twice the duct pitch, $d_{h}=2 b$.

$$
\begin{aligned}
& f \operatorname{Re}=\left[\left(f \operatorname{Re} e_{\text {developing }}\right)^{2}+\left(f \operatorname{Re} e_{\text {developed }}\right)^{2}\right]^{0.5} \\
& f R e_{\text {developing }}=\frac{3.44}{\sqrt{L^{*} P r}}
\end{aligned}
$$

where, $L^{*}=x / D_{h} \operatorname{PrRe}$

$$
\begin{aligned}
f \operatorname{Re}_{\text {developed }}= & 24-32.527\left(\frac{b}{H}\right)+46.721\left(\frac{b}{H}\right)^{2}-40.829\left(\frac{b}{H}\right)^{3} \\
& +22.954\left(\frac{b}{H}\right)^{4}-6.089\left(\frac{b}{H}\right)^{5}
\end{aligned}
$$

The relationship between the dimensionless friction factor and the pressure drop over a finned tube bank is presented in Equation (7) [7]. This equation accounts for four different phenomena which contribute to the overall pressure drop, flow losses at the inlet to the core, the core frictional loss, momentum effects and pressure recovery at the core outlet. In the case of the circular finned tube designs the inlet and exit losses are accounted for in the core frictional term [7,25]. However, as a theoretical approach is used for the plate finned design these factors must be accounted for. $K_{c}$ and $K_{e}$ are coefficients to account for the entrance and exit effects. The value of these coefficients has been correlated by Ref. [26] for common heat exchanger surfaces and can be calculated based on the ratio for frontal to free flow area.

$$
\begin{aligned}
\frac{\Delta p}{p_{i}}=\frac{G^{2}}{2 g_{c} \rho_{i} p_{i}}[\underbrace{\left(1-\sigma^{2}+K_{c}\right)}_{\text {entrance effect }}+\underbrace{f \frac{L}{r_{h}} \rho_{i}\left(\frac{1}{\rho}\right)_{m}}_{\text {core friction }} \\
+\underbrace{2\left(\frac{\rho_{i}}{\rho_{o}}-1\right)}_{\text {momentum effect }}-\underbrace{\left(1-\sigma^{2}-K_{e}\right) \frac{\rho_{i}}{\rho_{0}}}_{\text {exit effect }}]
\end{aligned}
$$

where, $K_{c}=0.42\left(1-\sigma^{2}\right)$ and $K_{e}=\left(1-\sigma^{2}\right)^{2}$

\subsection{Heat transfer}

The correlation of Briggs and Young [6] relates the Reynolds number of the flow with the Colburn factor $\left(\mathrm{StPr}^{2 / 3}\right)$, a nondimensional heat transfer characteristic. This correlation was used to predict the thermal performance of the circular finned tube condenser designs and is listed below in Equation (8). This correlation is valid within the flow range of $1100<R e<18,000$.

$S t P r^{2 / 3}=0.134 \operatorname{Re}^{-0.319}\left[\frac{2\left(S_{f}-\delta_{f}\right)}{d_{\mathrm{fin}}-d_{\mathrm{ex}}}\right]^{0.2}\left(\frac{S_{f}-\delta_{f}}{\delta_{f}}\right)^{0.1134}$

where, $\operatorname{StPr}^{2 / 3}=h / \rho u c_{p} \operatorname{Pr}^{2 / 3}$
Equation (9) presents an additional correlation factor developed by Gianolio and Cuti [15], to be used with Equation (8) to compensate the reduction in heat transfer for reduced tube rows. The resulting coefficient is essentially a fraction of the heat transfer characteristic for a given number of tube rows divided by that of a six row design, after which Equation (8) remains valid.

$\frac{\operatorname{StPr}_{n_{r}}^{2 / 3}}{\operatorname{StPr}_{6}^{2 / 3}}=\left(1+\frac{u_{\max }}{n_{r}^{2}}\right)^{-0.14}$

The correlation proposed by Nir [14] which again relates the Colburn factor to the Reynolds number and various geometrical features of the heat exchanger is shown in Equation (10). As for Equation (2), this correlation is valid over $300<R e_{h}<10,000$.

$S t P r^{2 / 3}=\operatorname{Re}^{0.4}\left(\frac{A_{\mathrm{min}}}{A}\right)^{-0.266} R_{b}^{-0.4}\left(\frac{d_{\mathrm{fin}}}{d_{\mathrm{ex}}}\right)^{-0.4} K_{h}$

where,

$R_{b}=S_{t}-d_{\text {fin }}+\left[\left(d_{\text {fin }}-d_{\mathrm{ex}}\right)\left(1-\delta N_{f}\right)\right] /\left[\left(d_{\text {fin }}-d_{\mathrm{ex}}\right)\left(1-\delta N_{f}\right)\right]$

The correlation of T'Joen et al. [16] for the Colburn factor across a single row finned tube heat exchanger is presented in Equation (11) for $1000<\operatorname{Re}<15,000$.

$S t P r^{2 / 3}=0.495 \operatorname{Re}^{-0.491} \operatorname{Pr}^{-1 / 3}\left(\frac{S_{t}}{d_{o}}\right)^{-0.209}$

The heat transfer from the plate fin design is determined in a similar fashion to the pressure drop in that a composite model is required to estimate the heat transfer in both the developing and developed sections of the finned ducts. The Nusselt number, an alternative heat transfer characteristic, is constant for fully developed laminar flow in ducts with constant cross sectional area, but does depend on the flow passage geometry and boundary conditions. The Nusselt number for fully developed flow in a rectangular duct with an isothermal boundary condition may be calculated using Equation (12) [25]. The influence of duct shape in the developing region is not as great and the relationship developed by Ref. [12] given in Equation (13) provides a reasonable Nusselt number results in this region.

$$
\begin{aligned}
N u_{\text {developed }}= & 7.741\left(1-2.610\left(\frac{b}{H}\right)+4.970\left(\frac{b}{H}\right)^{2}-5.119\left(\frac{b}{H}\right)^{3}\right. \\
& \left.+2.702\left(\frac{b}{H}\right)^{4}-0.548\left(\frac{b}{H}\right)^{5}\right)
\end{aligned}
$$

$N u_{\text {developing }}=\left(\frac{0.664}{\sqrt{L^{*} \operatorname{Pr}^{1 / 6}}}\right)\left(1+7.3 \sqrt{\operatorname{Pr} L^{*}}\right)^{0.5}$

where,

$N u=\frac{h d_{h}}{k}$

The overall Nusselt number where the flow is developing in the entrance region and fully developed downstream of this point, can again be represented using the intersection of asymptotes method [11]

$N u=\left[N u_{\text {developed }}^{1.5}+N u_{\text {developing }}^{1.5}\right]^{1 / 1.5}$ 


\subsection{Fan laws}

Equations (15)-(17) represent the three fan laws presented by Refs. [27] and [28] and can be used to modify manufacturer characteristic curves to generate fan characteristics at various speeds. Once integrated with pressure drop calculations from Equation (7), the condenser air-side flow rate, pressure-drop and fan power can be predicted.

$\dot{V} \propto N D^{3}$

$\Delta p \propto \rho N^{2} D^{2}$

$P_{f} \propto \rho N^{3} D^{5}$

\section{Experimental details}

\subsection{Full-scale test facility}

To characterize the air-side thermal and aerodynamic performance of the condenser designs, a steady state test facility which used condensing steam inside the tubes of the test core was designed. The test methodology was similar to that employed by Kays and London [7]. By passing significantly more steam through the tubes than what can be condensed, the thermal resistance from the steam to the tube inner surface is minimized and an isothermal heat exchanger surface can be achieved. Therefore the steam temperature can be assumed equal to the wall temperature, and so the sensors mounted in the steam core flow can be used to infer the wall temperature which is necessary to determine the wall to air heat transfer coefficient.

Fig. 2 is a side elevation of the full-scale test facility. The condenser module comprising of a finned tube bank (1), an inlet header (2) and an outlet header (3), was suspended in a structural steel frame allowing its inclination to be varied. The module was coupled to an array of axial fans (4). Steam was supplied to the inlet header (2) from an industrial steam boiler and passed through a series of valves to ensure it was in a superheated condition and slightly elevated above atmospheric pressure upon entering the condenser at (5). A positive pressure is essential to ensure air and other non-condensables do not enter the condenser which would create temperature non-uniformities. Providing steam in a superheated condition enables a precise calculation of the enthalpy at inlet of the condenser. The magnitude of superheat was regulated throughout the process and limited to $5{ }^{\circ} \mathrm{C}$ to ensure that the resultant sensible cooling was less than $1 \%$ of the latent heat of condensation and therefore negligible in comparison to the heat removed by the air. At the outlet header (3), the excess steam was separated from the condensate and vented away to the atmosphere (6). The condensate was gathered in the condensate tank (7) and pumped back to the boiler by the condensate pump (8). The tank was fitted with level switches which automatically controlled the pump to allow a precise mass of condensate be collected during each test iteration. The time required to collect this mass of condensate was recorded to calculate the condensate mass flow rate. The condensate temperature was also monitored to ensure no significant sub cooling occurred.

Pressure tappings were fitted to the walls of the fan enclosure (10) and connected to a 0-200Pa manometer to measure the airside pressure drop across the condenser. The inlet header was equipped with a series of vac-4bar absolute pressure transducers to measure the steam pressure. The outlet header was open to atmosphere to allow the excess steam leave the system and therefore atmospheric pressure was assumed. Air temperatures were measured at the test core inlet and outlet to calculate necessary properties. The air temperature was measured with thermistors which were integrated into one arm of a Wheatstone bridge for higher sensitivity and noise rejection. Steam temperatures were measured using K-type thermocouples at certain points in the steam supply line as well as at the inlet and outlet headers.

A series of velocity sensors were installed at the inlet and exit to the tube bundle (11). The velocity sensors were a series of thermistors individually incorporated into a Wheatstone bridge and an excitation voltage carefully selected to induce internal heating in the thermistors. The thermistors were calibrated in a wind tunnel to generate a relationship between air velocity and cooling rate of the thermistor. By implementing this calibration relationship, the air velocity past the thermistors could be inferred. This method of measuring air velocity was developed by Walsh et al. [3] and

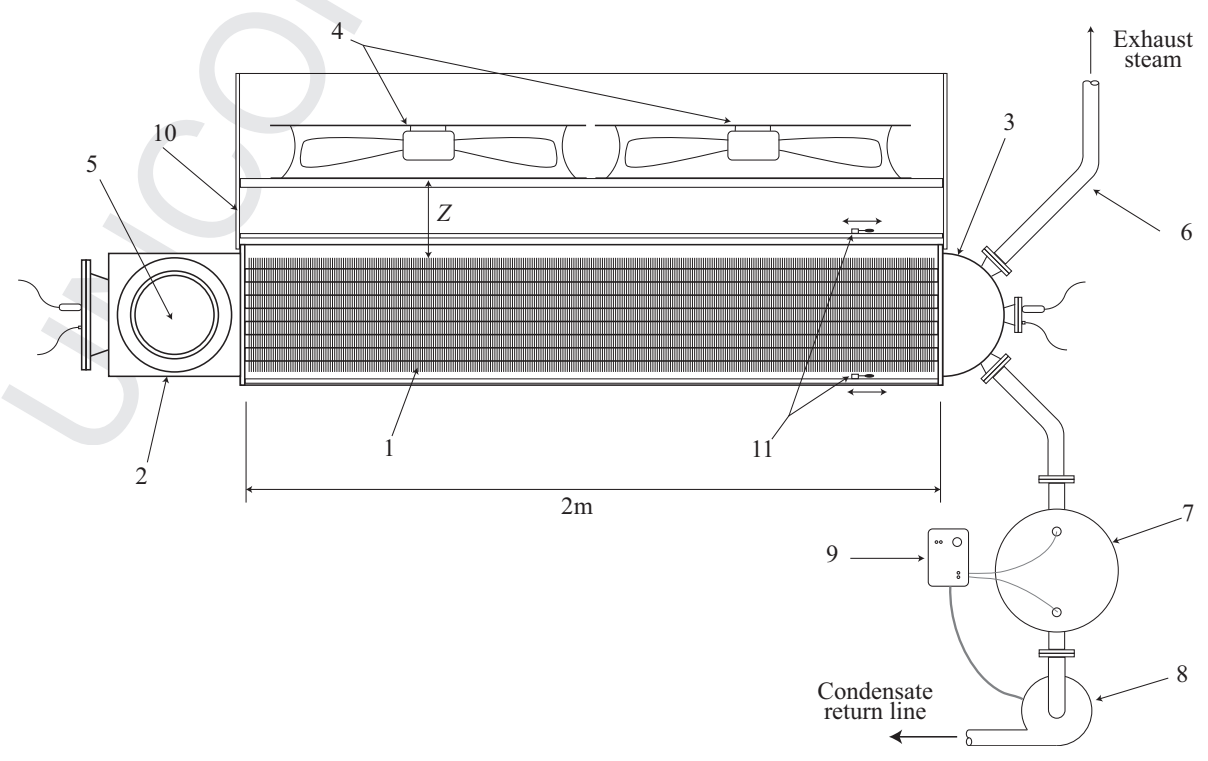

Fig. 2. Schematic diagram of the full-scale prototype test facility. 
calibration details and resistance constants can be found in Ref. [3]. In this study, 32 sensors were installed across the width of the condenser module and the rail of sensors was traversed in increments of $50 \mathrm{~mm}$ across the face of the module. This equates to a spatial resolution of $60.6 \mathrm{~mm}$ and $50 \mathrm{~mm}$ along the width and length of the module respectively. The temperature of each sensor was first recorded in each position, the excitation voltage was then increased and the thermistors were used to measure velocity using the calibration.

\subsection{Reduced-scale test facility}

Similar to the full-scale facility, a steady-state measurement technique using condensing steam was again employed. This test facility was more similar to the conventional method of characterising heat exchanger surfaces in that it employed a wind tunnel flow through a heat exchanger core. Due to laboratory constraints it was not possible to heat the entire core at once, and instead a method of heating one tube in different locations was deduced. The method of heating just one tube was employed by Kays and London [29], and successfully verified by comparing results to full scale test results with every tube heated. Further details of the data reduction in this test method are explained in the following section.

Fig. 3 is a schematic diagram of the reduced-scale condenser test rig. The main component is the wind tunnel section (6) which encloses a bank of circular finned tubes. The custom working section was $0.3 \mathrm{~m}$-square and $0.75 \mathrm{~m}$ long and fitted to an open-circuit suction design wind tunnel. The section was fitted with wall tappings (7) and (8) to measure the difference in air-side static pressure at inlet and outlet of the tube bank. A \pm 250 Pa pressure transducer was used to measure the pressure drop across the tube bundle. The downstream pressure tapping (8) was positioned far enough downstream to ensure a uniform flow field and an accurate measurement. Steam was supplied to the tube bank from a steam boiler (1) and passed through a baffle plate separator (2), where most of the liquid phase was removed. Steam pressure at inlet and outlet of the tube was measured using absolute pressure transducers (4) and (10). Steam temperature was also measured at the inlet and outlet of the condenser using K-type thermocouples (5) and (9). Upon exit from the condenser this excess steam was separated from the condensate and vented away. The condensate was gathered, weighed (11) and the time taken was recorded to determine the mass flow rate. A pitot static tube was positioned upstream of the condenser to measure the air flow velocity entering the core. This was traversed across the section and averaged to account for the boundary layers over the section walls. Air temperatures were measured at the test core inlet to calculate necessary properties. The air temperatures were measured with thermistors and all instrumentation was synchronized with a LabView 2011 data acquisition VI which also controlled the wind tunnel flow rate.

\section{Data reduction}

\subsection{Full-scale test facility}

By applying an energy balance to the test system and, as explained in Section 3.1, ensuring that there was negligible sensible cooling of the steam or the condensate, the heat rejected by the condenser was equivalent to the product of the mass flow of condensate times the enthalpy of vaporization as indicated in Equation (18). The overall heat transfer conductance, $U$, was calculated from the measured heat rejection using Equation (19). The air-side heat transfer coefficient, $h$, can be extracted from the overall conductance, $U$, using the thermal resistance model given in Equation (20) [7,25]. To extract $h$, the steam-side conductance is required but as the steam-side resistance is generally less than 5$10 \%$ of the total resistance in such a test scenario, an estimate of $h_{c}$ will suffice [29]. The remaining terms in Equation (20) are constants apart from $\eta_{\text {surf, the air-side surface effectiveness. This }}$ effectiveness is dominated by the fin effectiveness which, from the work of Gardner [31], can be calculated using Equation (21). The overall surface effectiveness, $\eta_{\text {surf, }}$ is a weighted average of the effectiveness of the prime surface and less than $100 \%$ of the fin surface as described in Equation (22) [7]. The experimental heat transfer coefficient was expressed in non-dimensional form for comparison with literature.

$$
\begin{aligned}
& Q_{\mathrm{rej}}=\dot{m}_{c} h_{f g} \\
& \varepsilon=1-e^{-\frac{U A}{C_{\mathrm{min}}}}=\frac{\dot{m}_{a} c_{p}\left(T_{O_{a}}-T_{\infty}\right)}{\dot{m}_{a} c_{p}\left(T_{S}-T_{\infty}\right)}=\frac{Q_{\mathrm{rej}}}{\dot{m}_{a} c_{p}\left(T_{S}-T_{\infty}\right)}
\end{aligned}
$$

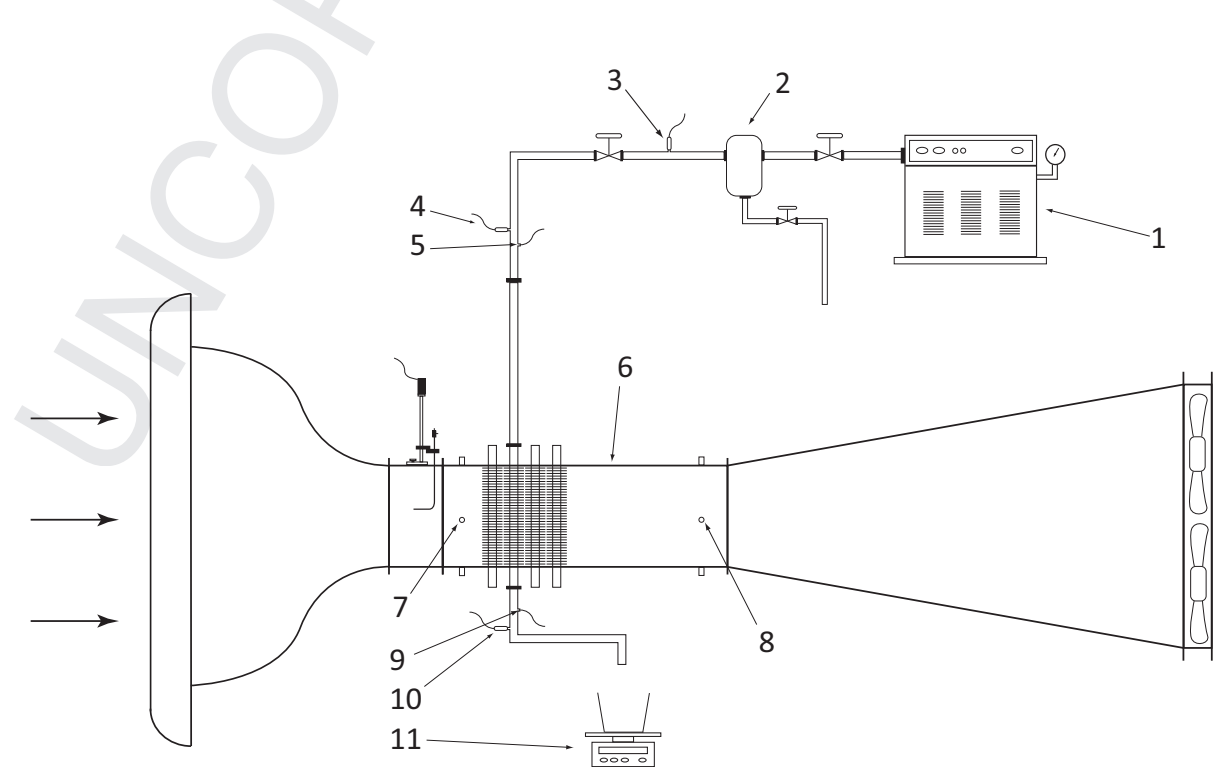

Fig. 3. A schematic diagram of the reduced-scale test facility. 


$$
\begin{gathered}
\underbrace{\frac{1}{U A}}_{\begin{array}{c}
\text { Overall thermal } \\
\text { resistance }
\end{array}}=\underbrace{\frac{1}{\eta_{\text {surf } h A}}}_{\begin{array}{c}
\text { air-side } \\
\text { resistanc }
\end{array}} \\
\eta_{f}=\frac{\tanh m l}{m l} ; \quad m=\sqrt{\frac{2 h}{k \delta}} \\
\eta_{\text {surf }}=1-\frac{A_{f}}{A}\left(1-\eta_{f}\right)
\end{gathered}
$$

The air-side pressure drop across the condenser was directly measured using a digital monometer. The measured pressure drop was then expressed non-dimensionally using Equation (7) for comparison with the respective correlations.

\subsection{Reduced-scale test facility}

In a tube bundle where all tubes are heated, as the air moves downstream through the core there is a substantial gain in temperature per row of tubes. This means that tubes at the rear of the bank experience a higher local inlet air temperature than those at the front. This significantly reduces the available temperature difference for cooling in this region. As only one tube is heated in the reduced scale experiments, this effect must be accounted for by calculating the rise in temperature which would occur if all tubes were heated (i.e. the air inlet temperature for downstream tubes).

As with the previous technique the heat rejected from a single tube was equivalent to the mass flow of condensate times the enthalpy of vaporisation. The heat rejected by that tube row at the ambient air conditions is given by Equation (23). A row by row analysis was then performed, starting at the first row where the ambient temperature is known. The effectiveness and the outlet temperature were calculated for that tube row using Equations (24) and (25) respectively. This outlet air temperature is the inlet temperature for the next tube row. The heat dissipated by a tube in the next row was measured at the ambient temperature. To determine the heat that this tube would dissipate if all tubes were heated, its measured heat rejection was multiplied by a ratio of the specific row, inlet-to-wall temperature difference, to the ambient-to-wall temperature difference. This relationship is shown in Equation (26), and corrects the measured heat dissipation at ambient conditions for the scenario when all the upstream tubes are heated. This process continues for the number of rows in the condenser and the total heat dissipated is calculated using Equation (27).

$Q_{r_{j \infty}}=\dot{m}_{c_{r j}} h_{f g} n_{t_{r_{j}}}$

$\varepsilon_{r_{j}}=\frac{Q_{r_{j}}}{\dot{m}_{a} c_{p}\left(T_{S}-T_{o_{r_{(j-1)}}}\right)}=\frac{T_{o_{r_{j}}}-T_{o_{r_{(j-1)}}}}{T_{S}-T_{o_{r_{(j-1)}}}}$

$T_{o_{r_{j}}}=\varepsilon_{r_{j}}\left(T_{S}-T_{i_{r_{j}}}\right)+T_{i_{r_{j}}}$

where, $T_{o_{r_{(j-1)}}}=T_{i_{r_{j}}}$

$Q_{r_{j}}=Q_{r_{\infty}}\left[\frac{T_{S}-T_{i_{r_{j}}}}{T_{S}-T_{\infty}}\right]$

$Q_{\mathrm{rej}}=\sum_{j=1}^{n_{r}} Q_{r_{j}}$
The corresponding overall heat transfer coefficient is a function of the total heat dissipated and was calculated using Equations (19) and (22), identical to the process described in the previous subsection.

\subsection{Uncertainty analysis}

To indicate the quality of the experimental measurements, an uncertainty analysis was performed according to the root-sumsquare method presented by Refs. [32] and [33]. The results of the uncertainty analysis for the reported results are listed in Table 1.

\subsection{CSP plant analysis}

The aim of this analysis was to develop a thermodynamic model to calculate the effect of various condenser parameters on power plant output. Therefore, during the analysis, the only parameters which were varied were those relating to the condenser. All others, such as turbine inlet steam temperature and flow rate were kept at constant values, representative of those in a parabolic trough CSP steam turbine under typical conditions of solar radiation. Fig. 4 presents performance characteristics from such a steam turbine operating in a $50 \mathrm{MW}$ parabolic trough CSP plant [34]. The model was developed to calculate three quantities, steam turbine gross power output, condenser fan power consumption, and net plant power output. The model calculated these quantities according to the following procedure:

1. The ambient temperature, number of modules in the condenser and the fan rotational speed were set

2. The variation of the condenser air-side pressure drop with flowrate was calculated using Equations (1)-(7), depending on the condenser design

3. For the given fan speed, a fan performance pressure flow characteristic plot was generated using fan manufacturer characteristics and the fan scaling laws, Equations (15)-(17)

4. The intersection between the system pressure flow characteristic curve and the fan performance characteristic curve was solved. This indicated the pressure drop across and the flow rate through the condenser module for the given fan rotational speed

5. The dimensionless heat transfer parameter (Nusselt number or Colburn factor), depending on the condenser geometry, was evaluated using experimental measurements and Equations 814

6. The corresponding heat transfer coefficient was determined from the Nusselt number or Colburn factor

7. The fan power consumption was calculated using a combination of the fan laws (Equations (15)-(17)) and the fan manufacturer data

Table 1

A list of uncertainty results on the reported variables.

\begin{tabular}{llll}
\hline \multirow{2}{*}{ Parameter } & Full-scale measurements & & Reduced-scale measurements \\
\cline { 2 - 2 } & Uncertainty (\%) & \\
\hline$Q_{\text {rej }}$ & $2.9-3.0$ & $3.8-4.1$ \\
$\dot{m}_{a}$ & 5 & 2.5 \\
$\varepsilon$ & 6.2 & 6.8 \\
$U$ & 7 & 7.9 \\
$S t \operatorname{Pr}^{2 / 3}$ & 12.7 & 13.1 \\
$N u$ & 12.4 & - \\
$\operatorname{Re}$ & 5.3 & 3 \\
$L^{*}$ & 6.7 & - \\
$f$ & $5-5.6$ & $4.3-7.9$ \\
$f R e$ & $7.8-8.9$ & - \\
\hline
\end{tabular}




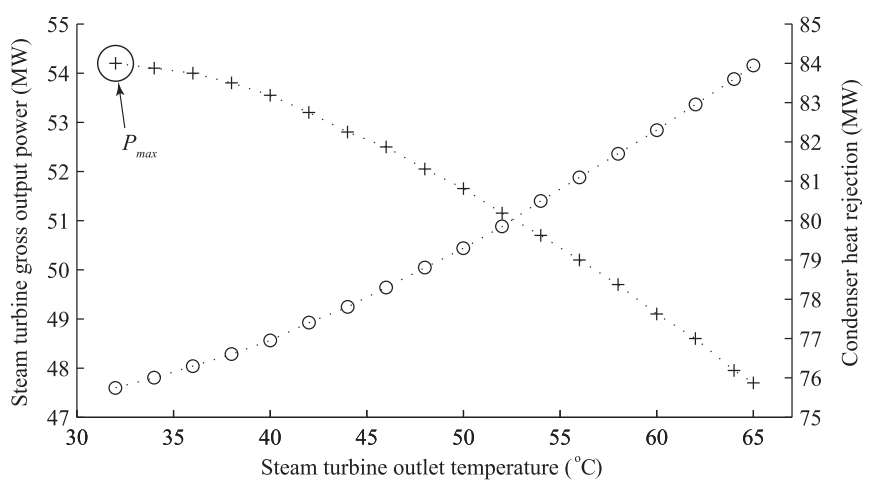

Fig. 4. Steam turbine outlet temperature versus the steam turbine gross output power and condenser heat rejection of a CSP plant operating under typical conditions.

8. Condenser temperature was determined from Equation (27) which governs the relationship between the condenser temperature, $T_{s}$, the condenser heat rejection, $Q$, which from the data in Fig. 4 can be expressed in terms of Ts, and the heat transfer coefficient, $h$

$$
\frac{Q}{\dot{m}_{a} c_{p}\left(T_{s}-T_{\infty}\right)}=1-e^{-\frac{\eta_{\text {surf }} h A}{C_{\text {min }}}}
$$

where,

$$
Q=\sum_{n=1}^{N} q_{n} T_{s}^{n-1}
$$

9. Once condenser temperature was solved, the gross turbine output power was calculated from an equation fitted to the steam turbine output curve which is presented in Fig. 4

10. Plant net output was calculated by subtracting fan power consumption from the gross steam turbine output

11. A plot of plant net power output versus fan rotational speed was generated by repeating steps 1 to 10 for a range of fan speeds

12. The previous steps were firstly repeated for different condenser sizes (number of modules) and secondly for different ambient temperatures, thus generating net plant performance data as a function of condenser size and ambient temperature.

Instead of expressing plant performance in terms of the net plant output, it may be more telling to express it in terms of efficiency loss due condenser performance as defined in Equation (29). The model does not take into account thermal steam side resistance. The authors are currently investigating steam side effects which are dependent upon numerous additional variables. However, preliminary steam-side measurements performed on the fullscale test facility showed that the steam side resistance is much less than the air-side and below $10 \%$ for most operational fan speeds.

$\eta_{\text {loss }}=\left(1-\frac{P_{\text {net }}}{P_{\text {max }}}\right) \times 100 \%$

The model does not take into account thermal steam side resistance. The authors are currently investigating steam side effects which are dependent upon numerous additional variables. However, preliminary steam-side measurements performed on the fullscale test facility showed that the steam side resistance is much less than the air-side and below $10 \%$ for most operational fan speeds.
To complete a comparison of the prototype designs a cost analysis was also required. In order to achieve this, a number of assumptions were necessary. To predict the installation cost, a number of manufacturers and industrial partners were consulted and the following relationship, Equation (30), was determined to estimate the capital cost in US\$. The relationship is based on the cost per unit mass of the constituent metals used in the respective design (i.e. steel tubes and aluminium fins) and the cost of the axial fans which is known. A scaling factor of 5 is also included to account for manufacture and installation of the condenser and is considered a conservative approach. A currency conversion or $€ 1=$ US\$1.36 was applied to calculate condenser cost in Euros.

$$
C c=\left\{\left[\left(M_{\text {alum }} \times C_{\text {alum }}\right)+\left(M_{\text {steel }} \times C_{\text {steel }}\right)\right] \times 5\right\}+C_{\text {fans }}
$$

The cost data was integrated into a techno-economic performance analysis to identify the ACC design which maximises plant output for minimum capital expenditure. The levelised cost of electricity was calculated for each condenser design and condenser size based on the optimum thermodynamic data. The LCOE analysis was based on the anaysis of [34], where an annual DNI factor of $2000 \mathrm{kWh} / \mathrm{m}^{2}$ and capacity factor of approximately $20 \%$ were used. The capital expenditure of the plant was estimated at $€ 4900 / \mathrm{kW}$ [34] plus the cost of the condenser calculated using Equation (30). The plant life was assumed to be 20 years and a standard discount rate of $6 \%$ was assumed. The levelised cost of electricity was calculated according to Equation (31) [22]

$\operatorname{LCOE}\left(\frac{€}{\mathrm{kWh}}\right)=\frac{I_{0}+\sum_{t=1}^{N_{t}} \frac{C_{t}}{(1+r)^{t}}}{\sum_{t=1}^{N_{t}} \frac{P_{\mathrm{el}}}{(1+r)^{t}}}$

where, $I_{0}$ is the capital expenditure of the CSP plant including the cost of the condenser applied at year zero and $C_{t}$ is the annual total costs made up of fixed and variable operation and maintenance costs. $P_{\mathrm{el}}$ is the annual net electricity output in $\mathrm{kWh}$ calculated from the gross output minus the fan power consumption. Other parisitic plant power consumption was assumed constant regardless of the condenser design and for this reason was omitted from this analsis. $r$ is the discount rate applied from year one onwards, $t$ the specific year of operation, and $N_{t}$ the plant litetime in years.

\section{Results and discussion}

This section firstly presents air velocity measurements at the inlet to the full scale condenser module under different flow conditions. Heat transfer and pressure drop measurements from the full-scale prototypes are then presented. Measurements from the reduced scale test facility for alternative circular finned tube designs follow and finally, the various condenser designs are compared in a plant analysis based on both thermodynamic efficiency and also the techno-economic performance.

\subsection{Flow field velocity measurements}

Fig. 5 presents three velocity contour plots from the inlet of the first full-scale prototype, a six row circular finned tube bank coupled with four axial fans. The velocity traverses were taken over one half of the module and it was assumed and verified with measurements, that the flow field was reasonably symmetrical about the centre line. The first contour, Fig. 5(a), shows a relatively uniform flow field produced from an induced draft fan arrangement. The fan to heat exchanger distance was $0.4 D_{f}$ and varying this distance had a negligible effect on the inlet flow field. The second contour, Fig. 5(b), is the inlet flow field generated by a forced draft 
flow field at a fan to heat exchanger distance of $0.4 D_{f}$. In this contour there are evident low velocity regions downstream of the fan hubs and also at the intersection of adjacent fans, i.e. as the airflows from adjacent fans collide. Annuli of high velocity air flow are present over the fan blade span. The final contour, Fig. 5(c), corresponds to a forced draft arrangement at a fan to heat exchanger distance of $0.75 D_{f}$. The low velocity regions are slightly less prevalent in this scenario, showing that increasing fan to heat exchanger distance increases the homogeneity of the air flow.

\subsection{Full-scale measurements - pressure drop}

Fig. 6 presents the pressure drop results for the six row and four row circular finned tube condenser designs, for both forced and induced draft air flows. The induced draft measurements show good agreement with the Robinson and Briggs [4] correlation, a $4.5 \%$ mean deviation for the four row design and $6.5 \%$ for the six row design. This is not surprising given that their data was measured in a uniform wind tunnel flow which as observed from the measurements presented in Fig. 5(a), is comparable to that produced in an induced draft scenario. The forced draft results do not match the correlated data as well and there are many possible factors which contribute to this. It is certainly intuitive to expect a higher pressure drop for the forced draft scenario due to flow separation as the swirling flow enters the core, particularly at the high velocity regions as illustrated in Fig. 5(b) and (c). However, pressure recovery also occurs as the radial component is removed from the flow as it straightens through the core. Many authors have reported on this phenomenon but few go into technical detail. Gianolio and Cuti [15] state that the conflicting phenomena cancel each other out and there is no significant difference between forced and induced draft pressure drop. Meyer and Kroger [35] and Beiler and Kroger [36] claim that in certain scenarios, pressure recovery is in fact greater than the additional pressure drop resulting in less fan power consumption for forced draft configuration. A greater issue is accurately measuring the forced draft pressure drop. Due to the size of the test facility the only feasible means of measuring the pressure drop was using wall pressure tappings. This requires parallel streamlines of air flow over the face of the tapping. While an

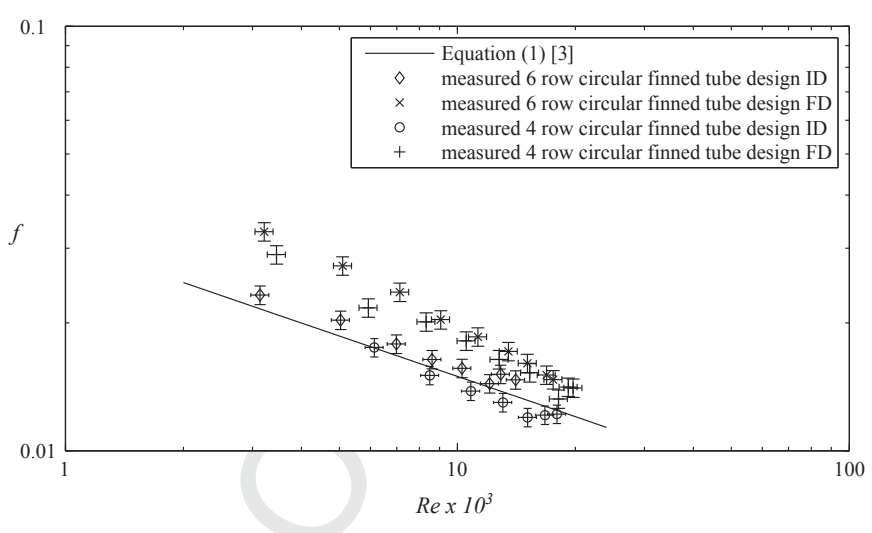

Fig. 6. A plot of friction factor against Reynolds number for circular finned tube condenser designs.

induced draft flow will reasonably satisfy this condition it is certainly not the case for a forced draft flow where tangential and radial velocity components are likely to cause flow impingement onto the wall. However, fan power consumption in both cases agreed well, suggesting that the pressure recovery which occurred balances out with the increased pressure drop which agrees with the findings of Gianolio and Cuti [15]. For the forced draft measurements, the mean deviations from the correlation of [4] for the four row and six row designs were $18 \%$ and $25 \%$ respectively. Further investigation is required to clarify the pressure recovery issue and identify what variables it is reliant upon.

Fig. 7 shows the pressure drop results for the plate finned tube condenser. The plot shows the analytical correlations for the nondimensional pressure drop in the entrance region, the fully developed region and also the composite model for full range of Reynolds number. Similar to the circular finned tube case the induced draft measurements agree very well with the correlation, with a mean deviation of $4 \%$. The forced draft measurements appear to be randomly scattered either side of the correlation again highlighting the difficulty in obtaining accurate forced draft measurements. These measurements had a mean deviation of $12 \%$ from the correlation. (a)

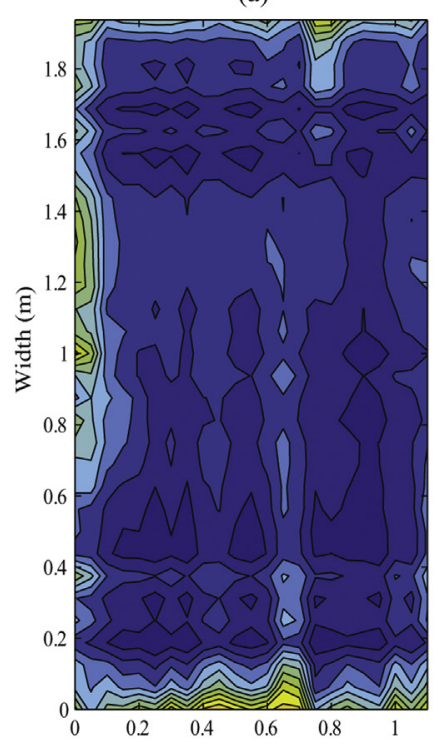

(b)

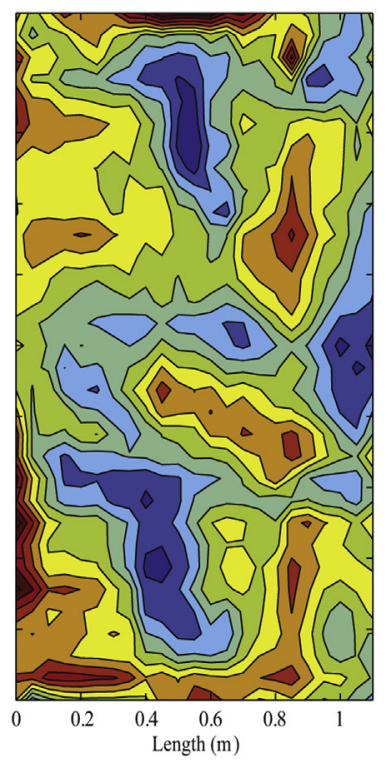

(c)

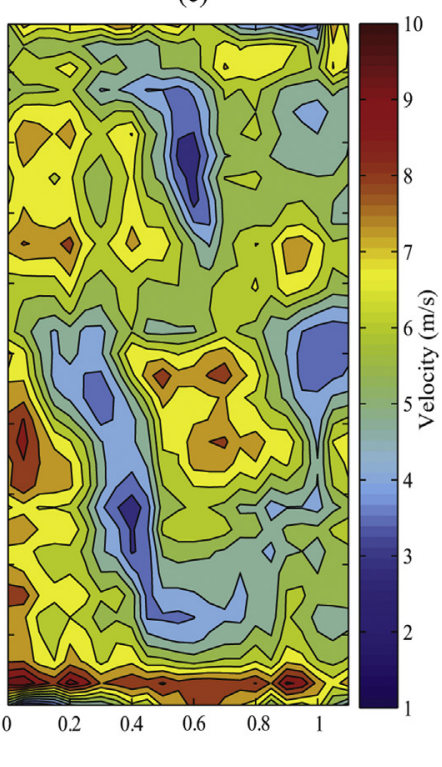

66

67

68

69

70

71
72

73

74

75

76

77

78

79

80

81

82

83

84

85

86

87

88

89

90

91

92

93

94

95

96

97

98

99

100

101

102

103

104

105

106

\section{7}

108

109

110

Fig. 5. Velocity contour plot at entrance to condenser for (a) induced draft flow at $Z=0.4 D_{f}$, (b) forced draft flow at $Z=0.4 D_{f}$ and $\left(\right.$ c) forced draft flow at $Z=0.7 D_{f}$. 


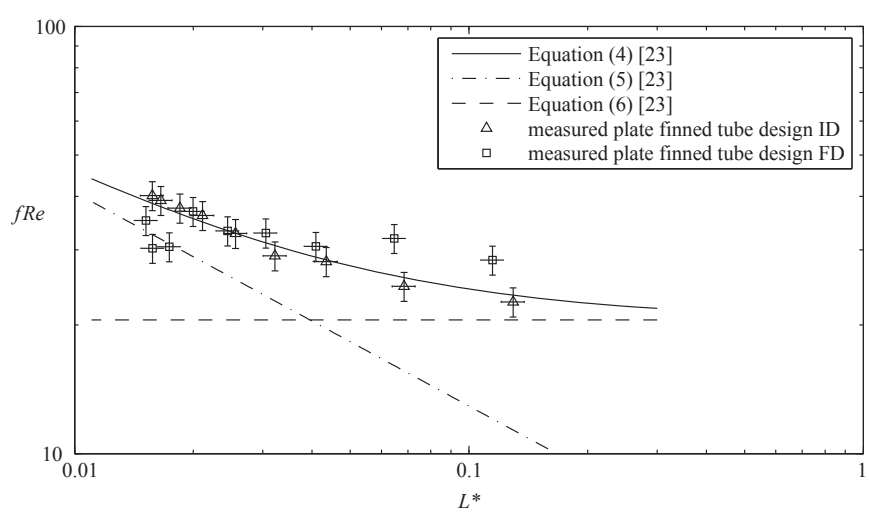

Fig. 7. A plot of the inverse Graetz number against friction factor Reynolds number product for the plate finned tube design.

\subsection{Full-scale measurements - heat transfer}

Fig. 8 presents the experimental heat transfer results for the six row and four row circular finned tube designs. The first point to note is that for both condenser designs the forced draft and induced draft results are in good agreement with each other. Due to the very different flow fields generated in each case, as shown in Fig. 5, this may not be intuitive. Further investigation underlines a number of reasons for this. Firstly, the condenser effectiveness, particularly at lower Reynolds numbers, is relatively high and therefore reduces the temperature difference and potential for further heat transfer. Another reason is what is commonly known in the literature as the row effect. For an induced draft flow, turbulence levels increase downstream of the first tube row due to vortices shedding from the fin structures. The turbulence level continues to increase throughout the downstream tube rows until it reaches a steady condition after approximately four to six tube rows. There are many different reports in the literature over the row effect and when exactly the turbulence level stabilises. Gianolio and Cuti [15] report that above four tube rows little row effect was found, whereas Monheit [7] concluded that the heat transfer from a three row tube bank was $97 \%$ of a five row tube bank. Some other authors including Jameson [37] and Mirkovic [38] predict row effects up to the eighth row. In the forced draft case, the same effect takes place downstream of the first tube row as well as an increase in the flow uniformity. The first tube row in this case may well be subjected to a flow with a higher turbulence intensity generated from the fan but as the banks are relatively deep this increase in terms of the overall heat transfer is not significant. The results show reasonable agreement, approximately $10 \%$ mean deviation, with the

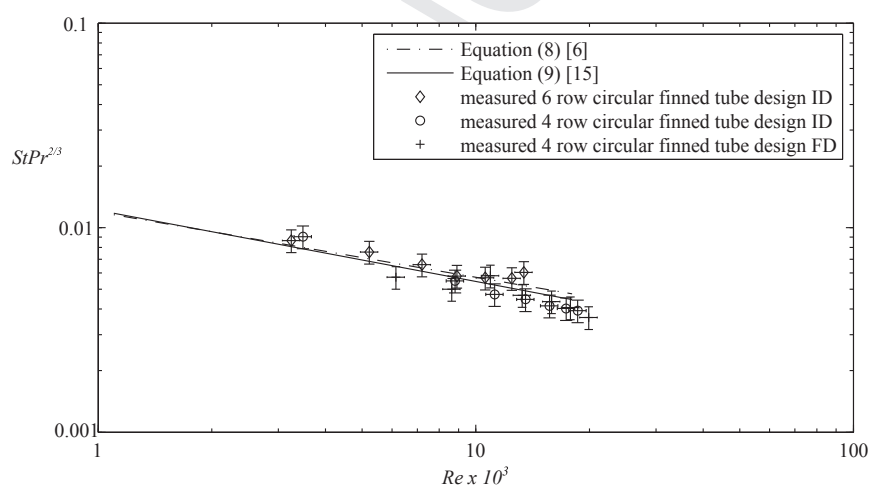

Fig. 8. A plot of the Reynolds number versus the Colburn factor for a six for and four row circular finned tube design.

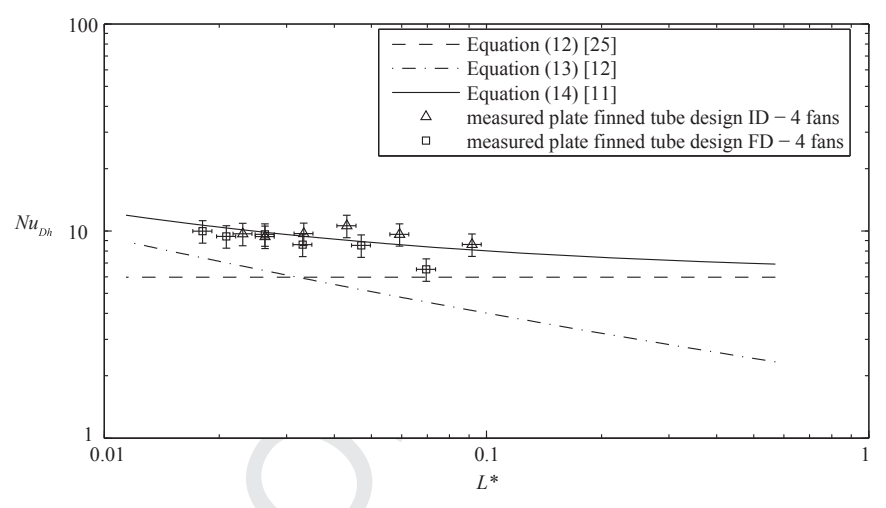

Fig. 9. A plot of the inverse Graetz number versus Nusselt number for the plate finned tube design.

correlations of Briggs and Young [6] and Gianolio and Cuti [15], verifying the use of both correlations for further analysis.

Fig. 9 is a plot of the plate finned tube condenser heat transfer measurements. In this case the analytical correlations for the flow in the two different regions of the finned duct are plotted along with a composite model to combine both regions. There is reasonable agreement between the measured values and the theoretical model, a mean deviation of $8 \%$. As for the previous designs, there is no effect on heat transfer between the forced and induced draft cases. However, in this case there are alternative reasons for this due to the different flow structures involved, although at the lower Reynolds numbers the issue of high effectiveness remains valid. In the case of the induced draft flow, the air flow is distributed relatively uniformly throughout the channels, resulting in a similar laminar flow and heat removal from the entire condenser. For the forced draft case the Nusselt numbers in the high velocity regions, seen in Fig. 5(b) and (c), become entrance region dominated and thus yield higher heat transfer coefficients. This increase in heat removal balances out with the reduced heat removal in the low velocity regions and therefore no significant difference in heat transfer is experienced.

\subsection{Reduced-scale measurements - pressure drop}

The aim of these measurements was to investigate how pressure drop varies with the number of tube rows for a circular finned tube design. Nir [14] and T'Joan et al. [16] provide unique correlations for pressure drop with various number of tube rows. The measurements shown in Fig. 10 show that six rows down to two tube rows

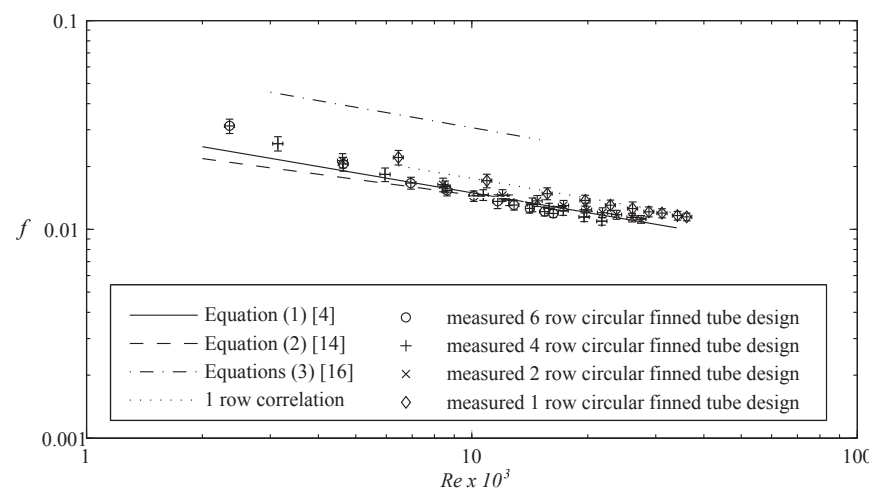

Fig. 10. A plot of the Reynolds number versus friction factor for a six, four, two and single circular finned tube design. 
agree very well with the correlation of Nir [14] and Robinson and Briggs [4]. For a single tube row both of these correlations under predict the pressure drop. A mean deviation of $6 \%$ was found for the six row design and $3 \%$ for the four and two row designs. The correlation proposed by Ref. [16] is for a single tube row but over predicts the pressure drop. However it should be noted that the tube and fin diameters in their study were smaller than that used in this investigation. In order to accurately predict the pressure drop across a single tube row condenser the authors suggest a new coefficient to be used with the correlation proposed by Ref. [4]. Instead of the suggested coefficient 9.465 , for a single row case 11.11 provides a root mean-square deviation of approximately $1 \%$ with the measured data.

\subsection{Reduced-scale measurements - heat transfer}

As previously discussed, reducing the number of tube rows has a significant effect on heat transfer performance. While the heat transfer performance may deteriorate as there is less mixing in the upstream rows than in the downstream rows, reducing the number of tube rows decreases both the flow resistance and the capital cost. Therefore it was necessary to characterise the heat transfer performance of condenser designs with different number of tube rows. Fig. 11 presents the results for a six row, four row, two row and single row condenser from the reduced-scale test facility. There is reasonable agreement with the respective correlations, and therefore reasonable agreement with the full-scale measurements, verifying the reduced-scale test technique. The correlations presented by Ref. [15] for a two row and single row heat exchanger fall considerably below correlation of Briggs and Young [6] for a tube bundle with more than four tube rows. This highlights the deterioration in heat transfer with the reduction in tube rows and the good agreement of the measurements also verify this result. A mean deviation of approximately $6 \%$ was experienced between the measurements and the respective correlations. While these measurements go some way to validate the use of the correlations in the following power plant analysis, the authors are currently investigating the performance of these designs in fan generated flows.

\subsection{Plant analysis}

Initially two condenser sizes were considered for the power plant analysis, $2602 \mathrm{~m} \times 2 \mathrm{~m}$ modules and $6502 \mathrm{~m} \times 2 \mathrm{~m}$ modules. Fig. 12 shows the performance of the plant in terms of net power output $\left(P_{\text {gross }}-P_{\text {fans }}\right.$ ) for the two condenser sizes at a range of ambient temperatures. For each condenser the performance is plotted against fan speed for ambient temperatures of $10^{\circ} \mathrm{C}, 20^{\circ} \mathrm{C}$

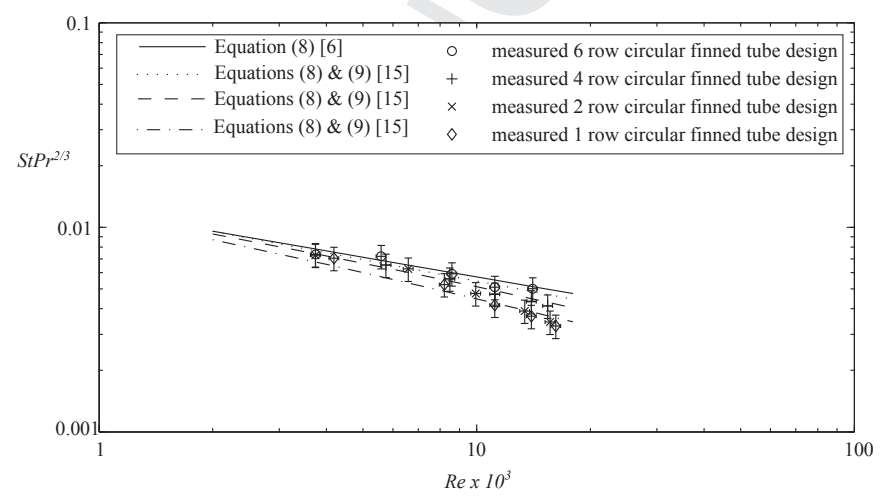

Fig. 11. A plot of the Reynolds number versus Colburn factor measurements for a two row and single row design, obtained from the reduced-scale test facility.

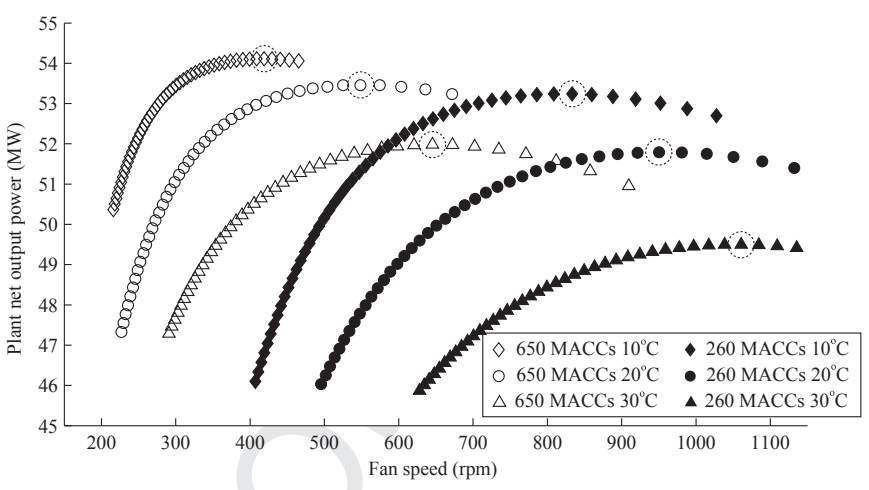

Fig. 12. A plot of module fan speed versus net plant output power for a four row circular finned tube condenser module at different ambient temperatures.

and $30{ }^{\circ} \mathrm{C}$. It should be noted that this plot is for the four row circular finned tube condenser with two axial fans positioned along the centre of the module. This plot shows the primary advantage of the technology; varying fan speed by just $100 \mathrm{rpm}$ can increase plant net output by over $10 \%$ in certain cases. Regardless of the condenser size or the ambient temperature there exists an optimum fan speed which yields the maximum net output power. Below this speed increasing the speed has the effect of reducing the turbine back pressure and hence increasing the gross turbine power by a greater magnitude than the increase in fan power. Above this speed further increases will continue to reduce the turbine back pressure but the increase in fan power is greater than the corresponding increase in gross turbine power. Thus it is important to consider fan power consumption when modelling plant performance with an ACC. It is also clear from Fig. 12 that increasing condenser size increases the plant output power, while increasing ambient temperature reduces the net output power.

The plot in Fig. 13 is an expansion of the thermodynamic analysis presented in Fig. 12 and compares the different condenser designs. Each data point represents the optimum plant operating point for the respective condenser size and design. For clarity purposes only the performance at the ambient temperature of $20{ }^{\circ} \mathrm{C}$ are plotted but the general trend remains constant regardless of temperature. The plant performance is calculated in terms of plant efficiency loss due to condenser operation as described by Equation (29) and the condenser size is plotted as condenser face area (or footprint area). The four row design and the plate finned design offer significant efficiency savings over the other designs, particularly at lower face areas. As the condenser size increases, a decrease in efficiency-loss is achieved due to the fact that the heat

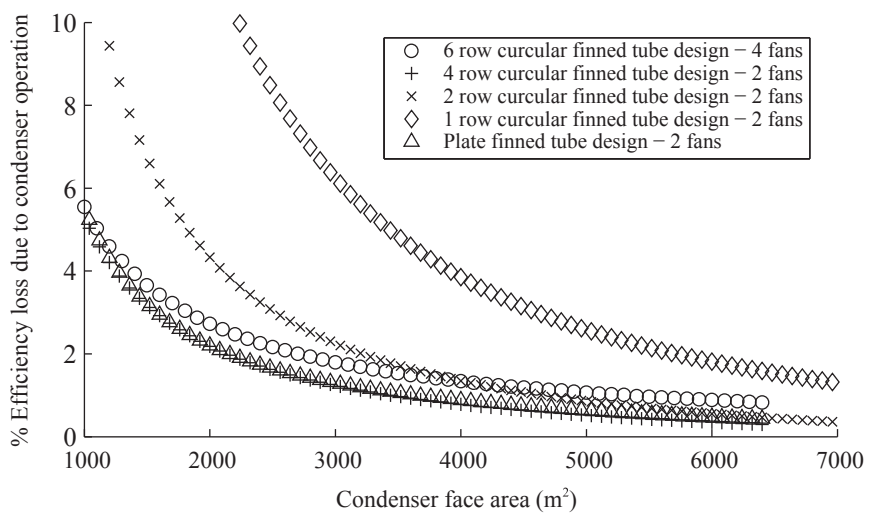

Fig. 13. A plot of condenser face area against plant efficiency loss due to condenser operation for various condenser designs. 
transfer area increases and the required fan speed reduces, thus reducing the total fan power consumption. This is very significant in terms of the single and two row circular finned tube designs. Since the flow resistance is much less, the reduction in fan power is even greater and as the condenser face area increases these designs become comparative in terms of their thermodynamic efficiency. However, increasing the condenser size also increases capital costs and footprint area. In some cases, particularly solar plants with a central tower, space is limited for a large condenser. Therefore there is a trade-off between efficiency, cost and available footprint area at the plant location.

Combining the optimum thermodynamic data presented in Fig. 13 with condenser and plant cost estimations, Fig. 14 presents a plot of the levelised cost of electricity generated by the plant over a 20 year lifetime against the specific plant capital cost in $€ / \mathrm{kW}$. Firstly this plot is an effective means of comparing the condenser designs in a single thermodynamic and economic metric. The plot also highlights the optimum size condenser (number of modules) for each of the designs. The initial design, six tube row module with four axial fans, performs poorly in comparison to the other designs. There are two contributing factors, firstly, the cost of the extra fans and tubes is considerable and secondly, the higher flow resistance leads to higher fan power consumption which has a negative effect on plant efficiency. A single row design is also quite poor in comparison to the remainder of the designs. As noted in the previous plot, as the size of this condenser increases, the efficiency loss of the single row design becomes competitive with other designs. However, in Fig. 14 it can be seen for this single row design to be competitive in terms of LCOE, the corresponding plant capital cost would increase by approximately $€ 50 / \mathrm{kW}$ relative to the other designs. The techno-economic performance of the three remaining designs is similar. The two row design provides the lowest LCOE of $€ 0.2907 / \mathrm{kWh}$ at a capital cost of $€ 5005 / \mathrm{kW}$. The four row circular finned tube design and plate finned tube design have an LCOE $0.25 \%$ and $0.33 \%$ respectively, greater than the two row design. However, they achieve these values at a capital cost of approximately $€ 5000 /$ $\mathrm{kW}$. It should be noted that the LCOE values calculated in this study may be higher than figures published in other studies such as [1] and [22]. This is largely due to a low capacity factor (20\%) for the CSP plant in question as it has no storage capacity. Discrepancies between different studies also arise from the inclusion or exclusion of plant self-consumption [22]. In this study the fan power consumption is included, a variable which is often overlooked.

\section{Conclusions}

In the first part of this study the heat transfer and friction characteristics of various condenser designs were measured. The following conclusions can be drawn from these measurements:

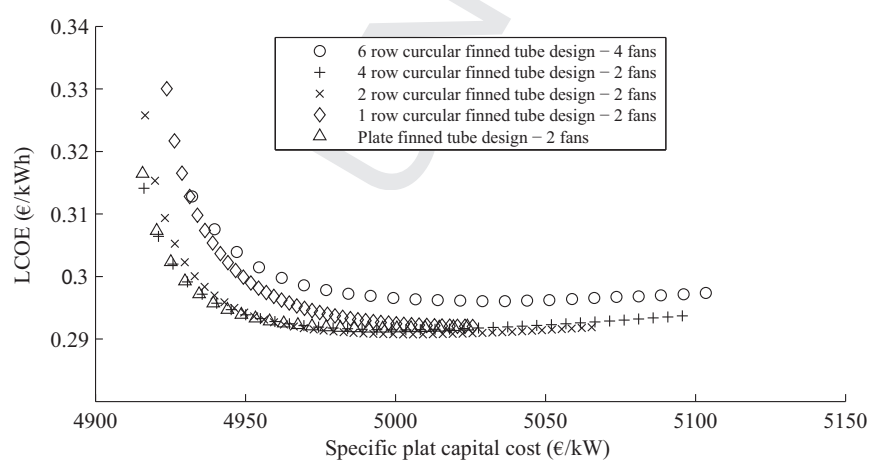

Fig. 14. A plot of CSP plant specific capital cost against LCOE for various condenser designs.
- The velocity measurements at the inlet to the condenser highlight the very different flow fields associated with forced and induced draft configurations. A uniform flow field was observed for the induced draft case. For the forced draft case the flow field was non-uniform but increased in uniformity as the fan to heat exchanger distance was increased

- Despite the different flow fields, no significant difference in heat transfer performance was observed between induced and forced draft cases. As previously explained this is most likely due to the high effectiveness of the designs tested and the row effect in the case of the circular finned tube bundles

- For the six and four row circular finned tube designs, reasonable agreement was found with the correlations of $[4,14]$ for pressure drop and $[6,14,15]$ for heat transfer. For the plate finned tube design, reasonable agreement was found with the analytical correlations of [23] for pressure drop and [11] for heat transfer.

- The two row and single row condenser designs were characterised in a reduced-scale, wind tunnel facility. Reasonable agreement was found with [15] for heat transfer. In terms of pressure drop good agreement was found between the measurements and the correlation of [4] for a two row heat exchanger. However for a one row heat exchanger the authors suggest a constant of 11.11 be used in Equation (1) rather than 9.465

The second part of this study focused on developing a model to predict the thermodynamic performance of a CSP plant to investigate the effect of various condenser design parameters on the thermodynamic efficiency and economic performance. The following conclusions can be drawn from this analysis:

- The thermodynamic model used correlations from literature, experimental measurements and output data from a 50 MW CSP plant, and was capable of calculating the net plant output at different condenser operating points and for different condenser sizes and designs

- The primary advantage of the proposed condenser technology is highlighted in this analysis. For any condenser size or ambient conditions, there exists an optimum fan speed which yields a maximum net plant output power. In certain scenarios altering fan speed by just $100 \mathrm{rpm}$ can increase plant output by $10 \%$

- A thermodynamic comparative analysis of the proposed designs showed that the best designs were the four row circular finned tube design and the plate finned tube design. At higher condenser face areas the two row circular finned tube design becomes competitive with these designs

- A techno-economic analysis of the plant was performed to compare the thermodynamic and economic performance of the designs in a single metric. This analysis showed the two row design to be the best performing design with an LCOE of $€ 0.2907 / \mathrm{kWh}$ at a CSP plant capital cost of $€ 5005 / \mathrm{kW}$. However the four row design and the plate finned tube design provide an LCOE just $0.25 \%$ and $0.33 \%$ higher respectively, with a $0.1 \%$ decrease in plant capital cost.

\section{Uncited references}

$[30,39]$

\section{Acknowledgements}

The research leading to these results has received funding from the European Union's Seventh framework Programme (FP\&/20072013) under grant agreement number 256797 as part of the 
MACCSol project [34]. The consortium of project partners consists of three universities and four industrial partners. The universities are the University of Limerick in Ireland, the University of Erlangen in Germany and the Universita Degli Studi di Perugia in Italy. The industrial partners involved are R\&R Mechanical Ltd. in Ireland, Torresol Energy Investments Ltd. in Spain, AuBren Ltd in Ireland and the Electricity Authority of Cyprus.

\section{Q3 References}

[1] SunShot vision study: February 2012. SunShot, Energy Efficiency and Renewable Energy, U.S. Department of Energy; 2012. NREL Report No. BK5200-47927; DOE/GO-102012-3037, http://www.solar.energy.gov/pdfs/ 48927.pdf.

[2] http://ec.europa.eu/energy/res/setplan/(The European Strategic Energy Technology plan).

[3] Walsh EJ, Grimes R and Griffin G. Flow distribution measurements from an air cooled condenser in a 400MW power plant, Prod ASME IMECE 2011.

[4] Robinson KK, Briggs DE. Pressure drop of air flowing across triangular pitch banks of finned tubes. Chem Eng Prog Symp Ser 1963;62(64): 177-83.

[5] Ward DJ, Young EH. Heat transfer and pressure drop of air in forced convection across triangular pitch banks of finned tubes. Chem Eng Prog Symp Ser 1959;55(29):39-46.

[6] Briggs DE, Young EH. Convective heat transfer and pressure drop of air flowing across triangular pitch banks of finned tubes. Chem Eng Prog Symp Ser 1963;59(41):1-10.

[7] Kays WM, London AL. Compact heat exchangers. Florida, USA: Krieger Publishing Company; 1998.

[8] Monheit M. Comparative experimental performance of high-finned tubes in staggered equilateral and equivelocity layouts. J Therm Fluid Sci 1988;1:7581.

[9] Zukauskas A. Heat Transfer from tubes in crossflow. Adv Heat Transf 1987;18.

[10] Bejan A, Kraus AD. Heat transfer handbook. Wiley; 2003.

[11] Teertstra P, Yovanovich MM, Culham JR. Analytical forced convection of plate fin heat sinks. J Electron Manuf 2000;10(4):253-61.

[12] Sparrow EM. Analysis of laminar convection-heat transfer in the entrance region of flat rectangular ducts - NACA technical note 3331; 1955.

[13] O’Donovan A, Grimes R, Walsh E, Moore J and Reams N. Steam-side characterisation of a modular air-cooled condenser, Proc ASME IMECE 2012, Houst TX, USA.

[14] Nir A. Heat Transfer and friction factor correlations for crossflow over staggered finned tube Banks. Heat Transf Eng 1991;12(1):43-58.

[15] Gianolio E, Cuti F. Heat Transfer and pressure drop for air coolers with different numbers of rows under induced and forced draft. Heat Transf Eng $1981 ; 3(1): 38-48$.

[16] T'Joen C, Huisseune H, Brodeoux P, Debaets S, De Paepe M. Thermal hydraulic study of a single row heat exchanger with helically finned tubes. J Heat Transf 2010;13.

[17] Wang CC, Webb RL, Chi KY. Data reduction for air-side performance of finand-tube heat exchangers. Exp Therm Fluid Sci 2000;21:218-26.
[18] Moore J, Grimes R and Walsh E. Influence of the flow from an axial fan on the performance of a heat exchanger, Proceedings ASME IMECE 2011, Denver, CO, USA.

[19] Huifang D, Boehm RF. An estimation of the performance limits and improvement of dry cooling on trough solar thermal plants. J Appl Energy 2011;88:216-23.

[20] Nithyanandam K, Pitchumani R. Cost and performance analysis of concentrating solar power systems with integrated latent thermal energy storage. Int J Energy 2014;64:793-810.

[21] Blancp-Marigorta AM, Sanchez-Henríquez MV, Pena-Quintana JA. Exergetic comparison of two different cooling technologies for the power cycle of a thermal power plant. Int J Energy 2011;36:1966-72.

[22] Fraunhofer ISE. studt: Levelised Cost Of Electricity, Renewable Energies. Fraunhofer Institute for Solar Energy systems; May 2012. Renewable Energy Innovation Policy, http://www.ise.fraunhofer.de/en/publications/studies/costof-electricity.

[23] Culham JR, Muzychka Y,S. Optimization of plate fin heat sinks using entropy generation minimisation. IEEE Trans Comp Packag Technol 2001;24(2):15965.

[24] Churchill SW, Usagi R. A general expression for the correlation of rates of transfer and other phenomena. Am Inst Chem Eng 1972;18:1121-8.

[25] Shah RK, Selulic DP. Fundamentals of heat exchanger design. New Jersey: Wiley; 2003.

26] White FM. Fluid Mechanics. New York: McGraw-Hill; 1987.

[27] Osbourne WC. Fans. $2^{\text {nd }}$ ed. Oxford: Pergamon Press; 1977.

[28] Berry $\mathrm{CH}$. Flow and fan - principles of moving air through ducts. $2^{\text {nd }}$ ed. New York: The Industrial Press; 1963.

[29] Kays WM, London AL. Heat transfer and friction characteristics for gas flow normal to tube banks-use of a transient-test technique. Trans ASME 1954;76(3):387-96.

[30] Kays WM, London AL. Heat transfer and friction characteristics of some compact heat-exchanger surfaces part 1-test system and procedure. Trans ASME; 1954.

31] Gardner KA. Mean temperature difference in an array of identical heat ex changers. Ind Eng Chem 1942;34:1083-7.

[32] Kline SJ, McClintock FA. Describing uncertainties in single-sample experiments. Mech Eng 1953;75:3-8.

[33] Coleman HW, Steele WG. "Experimentation and Uncertainty Analysis for Engineers". New York: Wiley; 1989.

[34] Poullikkas A, Grimes R, Walsh EJ, Hadjipaschalis I, Kourtis G. Optimal sizing of modular air-cooled condensers for CSP plants. J Power Technol 2013;93(3): $178-84$

[35] Meyer CJ, Kröger DG. Plenum chamber flow losses in forced draught aircooled heat exchangers. J Appl Therm Eng 1998;18:875-93.

[36] Beiler MG, Kröger DG. Thermal performance reduction in air-cooled heat exchangers due to nonuniform flow and temperature distributions. Heat Transf Eng 1996;17:875-93.

37] Jameson SL. Tube spacing in fin tube banks. Trans ASME 1945:67:633-42.

[38] Mirkovic Z. Heat transfer an flow resistance correlation for helically finned and staggered tube banks in cross flow. In: Afgan $\mathrm{NH}$, Schlunder EU, editors Heat exchangers: design and theory source book; 1974. pp. 559-84. Hemisphere, Washington DC

[39] www.drycooledcsp.eu (The development and verification of a novel modular air cooled condenser for enhanced concentrated solar power generation MACCSol, EC contract no. 256797). 